\title{
Welfare analysis of a zero-smoking policy - A case study in Japan
}

\author{
Yuuki Nakamura ${ }^{1}, K_{\text {Kenzo Takahashi }}^{2, *}$, Marika Nomura ${ }^{3}$, Miwako Kamei ${ }^{4}$ \\ ${ }^{1}$ Graduate School of Pharmacy, Nihon University, Chiba, Japan; \\ ${ }^{2}$ Graduate School of Public Health, Teikyo University, Tokyo, Japan; \\ ${ }^{3}$ Department of International Health and Collaboration, National Institute of Public Health, Saitama, Japan; \\ ${ }^{4}$ School of Pharmacy, Nihon University, Chiba, Japan.
}

\begin{abstract}
Summary Smoking cessation efforts in Japan reduce smoking rates. A future zero-smoking policy would completely prohibit smoking ( $0 \%$ rate). We therefore analyzed the social welfare of smokers and non-smokers under a hypothetical zero-smoking policy. The demand curve for smoking from 1990 to 2014 was estimated by defining quantity as the number of cigarettes smoked and price as total tobacco sales/total cigarettes smoked by the two-stage least squares method using the tax on tobacco as the instrumental variable. In the estimation equation (calculated using the ordinary least squares method), the price of tobacco was the dependent variable and tobacco quantity the explanatory variable. The estimated constant was 31.90 , the estimated coefficient of quantity was -0.0061 (both, $p<0.0004$ ), and the determinant coefficient was 0.9187. Thus, the 2015 consumer surplus was 1.08 trillion yen (US\$ 9.82 billion) (95\% confidence interval (CI), 889 billion yen (US\$ 8.08 billion) - 1.27 trillion yen (US\$ 11.6 billion)). Because tax revenue from tobacco in 2011 was 2.38 trillion yen (US\$ 21.6 billion), the estimated deadweight loss if smoking were prohibited in 2014 was 3.31 trillion yen (US\$ 30.2 billion) (95\% CI, 3.13 trillion yen (US\$ 28.5 billion) - 3.50 trillion yen (US\$ 31.8 billion)), representing a deadweight loss about 0.6 trillion yen (US\$ 5.45 billion) below the 2014 disease burden (4.10-4.12 trillion yen (US\$ 37.3-37.5 billion)). We conclude that a zero-smoking policy would improve social welfare in Japan.
\end{abstract}

Keywords: Tobacco, zero-smoking policy, welfare analysis, disease burden

\section{Introduction}

In Japan, smoking cessation is promoted based on the Healthy Japan 21 (second term) health and assessment project, in which the rate for adult smoking is set at $12 \%$ and the rate for underage (younger than age 18) smoking is set at $0 \%$. Due to smoking cessation efforts in Japan, smoking rates have declined in recent years (Figure 1). The next step in an anti-smoking policy would be the entire prohibition of smoking to achieve a smoking rate of $0 \%$, namely, a zero-smoking policy. In order to evaluate a zero-smoking policy, the social

Released online in J-STAGE as advance publication February 25, 2018.

*Address correspondence to:

Dr. Kenzo Takahashi, Teikyo University Graduate School of Public Health, 2-11-1 Kaga, Itabashi-ku, Tokyo 173-8605, Japan.

E-mail: kenzo.takahashi.chgh@med.teikyo-u.ac.jp welfare of both smokers and non-smokers must be considered. Even though a zero-smoking policy has not yet been discussed as actual policy by governments including that of Japan, this paper has examined how such a hypothetical policy would affect the social welfare of both smokers and non-smokers.

Three previous studies have estimated the disease burden due to smoking to be 3.96 (1), 7.15 (2), and 4.13 (3) trillion yen (US\$ 36.0, 65.0, and 37.5 billion, respectively, assuming $\$ 1=110$ yen (Table 1$)$ ). Although these numbers appear to differ substantially, a previous study by the current authors adjusted those numbers by standardizing the population of smokers in 1990 as 45.74 million and the unit cost of the opportunity cost (the willingness to pay for 1 qualityadjusted life year gain (4)) as 6 million yen. The resulting numbers were $7.34,7.35$, and 7.33 trillion yen (US\$ 66.7, 66.6, and 66.8 billion), respectively (4). If the population of smokers in 2014 is assumed to be 25.16 million, then the disease burden of smokers in 


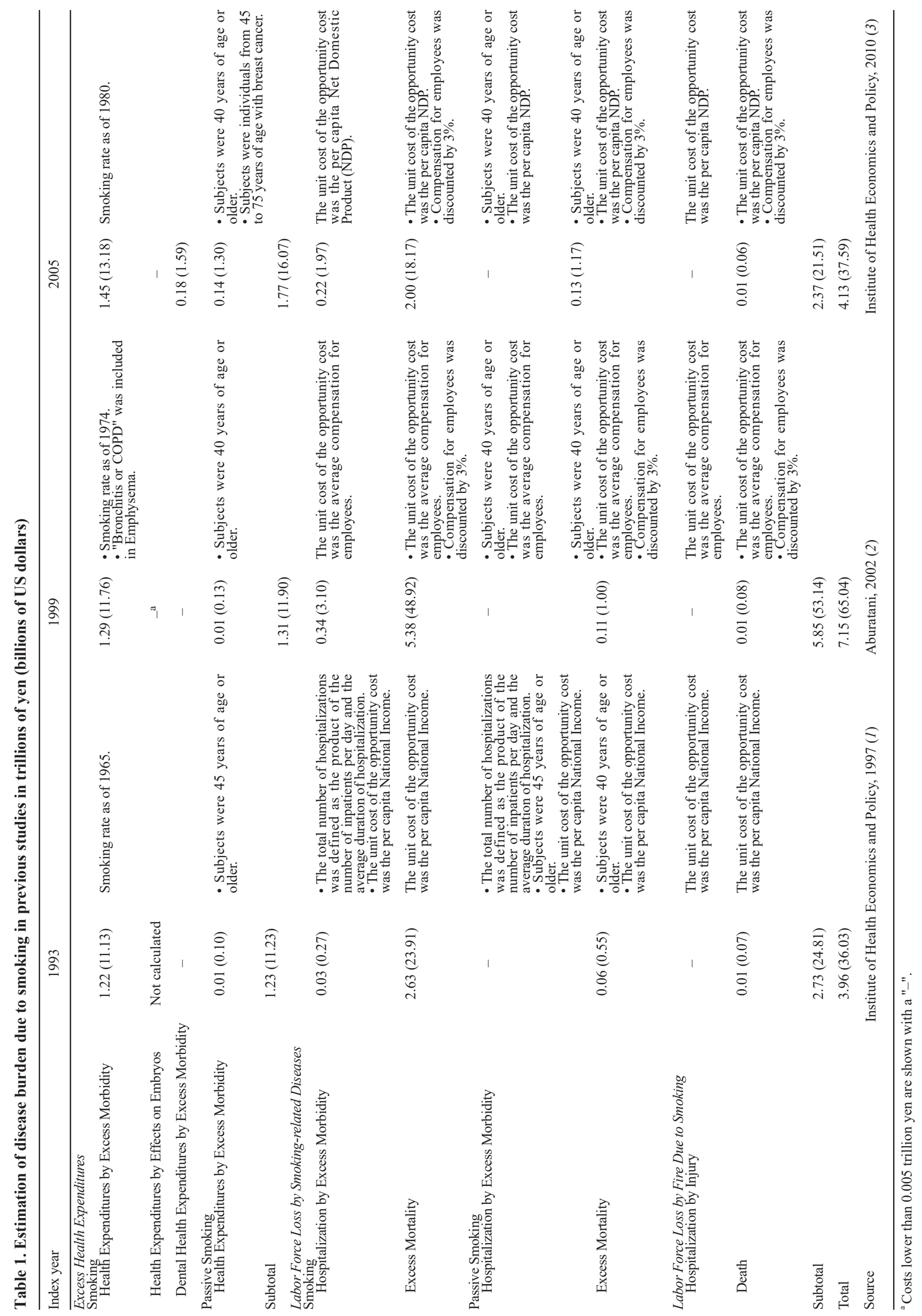


2014 could be estimated as 4.10-4.12 trillion yen (US\$ 37.3-37.5 billion). In any case, smoking poses a huge burden to society.

The disease burden due to tobacco was estimated to be $€ 21$ billion in Germany (5), US\$ 15.8 billion in California (6), US\$ 5.03 billion in China (7), US\$ 3.154.58 billion in South Korea (8), and US\$ 291-336 million in Taiwan (9). If these estimates are converted to per capita figures, then the disease burden would be $€ 286$ (assuming $€ 1=$ US\$ 1.1), US\$ 471.60, US\$ 4.05, US\$ 68.00-98.90, and US\$ 13.00-15.00. The disease burden per capita in Japan is US\$ 570, which seems to be larger than that in the countries or regions listed. However, populations, smoking rates, and the unit cost of the opportunity cost may differ by country, so international comparisons should be made with great caution.

Smoking differs from other diseases because smokers decide to smoke of their own free will and because smoking may have some utility for them. Needless to say, the disease burden is a negative externality for them, and thus they do not factor it when they assess smoking's utility. However, smokers are also members of society, so the utility they derive from smoking should not be ignored as long as smoking is evaluated from a societal point of view.

Thus, a zero-smoking policy could be rationalized if the deadweight loss due to the zero-smoking policy proves to be less than the disease burden. If not, a zerosmoking policy would be a welfare loss to society. To the extent known, such a welfare analysis has not been conducted. Therefore, this paper has examined the social welfare resulting from a zero-smoking policy.

\section{Methods}

A general demand curve for a good in a market is shown in Figure 2. According to basic economics, if tax rate $t$ were imposed on the consumer in this market, consumer surplus would be $a b g$, tax revenue would be gbeh, and thus deadweight loss should be bec, which is the welfare loss due to taxation. If the tax rate rises to $\mathrm{t}^{\prime}$ in Figure 3, demand for this good disappears, and thus consumer surplus and tax revenue must be zero. In this case, the deadweight loss would be $b^{\prime} e^{\prime} c$. Hence, a zero-smoking policy reduces social welfare by the amount of this deadweight loss, and thus the additional deadweight loss should be the consumer surplus plus tax revenue before prohibition in Figure 2. However, a society in which smoking is prohibited can earn as much as the disease burden due to smoking. If the deadweight loss is smaller than the disease burden, then the zero-smoking policy would be a welfare gain to society, but if not, the zero-smoking policy would be a welfare loss to society.

To estimate the demand curve for smoking, its quantity is defined as the number of cigarettes smoked, according to the Japan Tobacco Association (http:// www.tioj.or.jp/data/index.html), and its price is defined as the total amount of tobacco sales divided by the number of cigarettes smoked, deflated by the Consumer Price Index.

The demand curve for tobacco estimated was using the ordinal least squares method, with the price of tobacco serving as the dependent variable and the quantity of tobacco serving as an explanatory variable. The period studied was from 1990 to 2014. The price and the quantity of cigarettes smoked were determined simultaneously, and the two-stage least squares method was used with the tax on tobacco as the instrumental variable.

This study involved no ethical concerns since only previously published data were used.

\section{Results and Discussion}

Figure 4 shows the observed quantity and price as dots and the fitted line according to the two-stage least

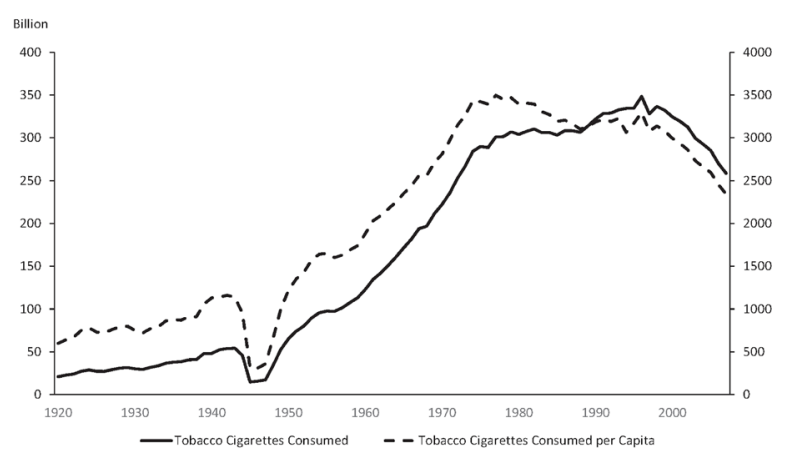

Figure 1. Tobacco use in Japan. The solid line represents the number of cigarettes smoked according to the Japan Tobacco Association (http://www.tioj.or.jp/data/index.html), and this number is scaled on the left-hand axis. The dashed line represents the number of cigarettes smoked per capita, which is divided by the population over 15 years, as was cited from http://www.health-net.or.jp/tobacco/product/pd070000. $\mathrm{html}$. This number is scaled on the right-hand axis. The authors created this figure from the data mentioned above.

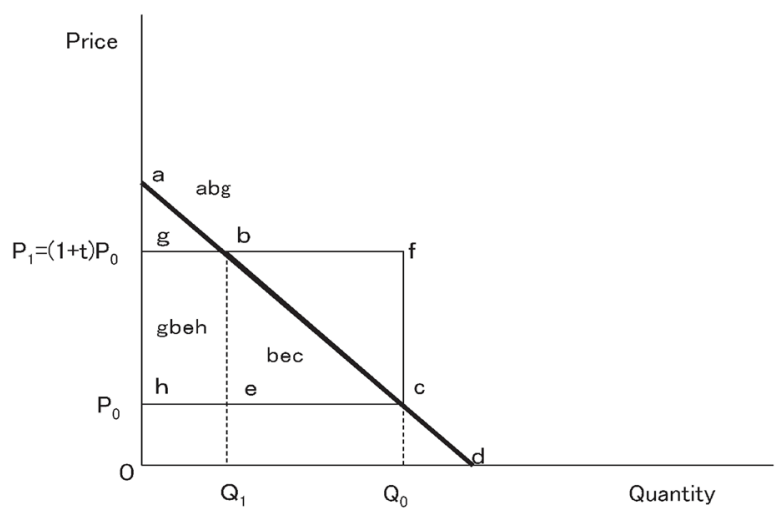

Figure 2. Demand curve for tobacco. In this market, the pyramid-shaped area of abg indicates consumer surplus, the square area of gbeh indicates tax revenue, and the pyramidshaped area of bec indicates deadweight loss. The authors created this figure. 


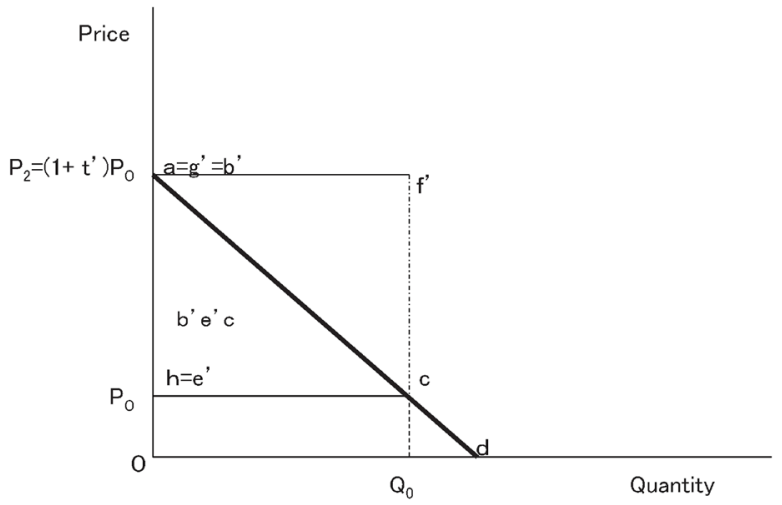

Figure 3. Deadweight loss due to a zero-smoking policy. If the tax rate rises to $t^{\prime}$, the quantity should be zero. In this case, deadweight loss would be the pyramidal shape of $b^{\prime} e^{\prime} c$. The authors created this figure

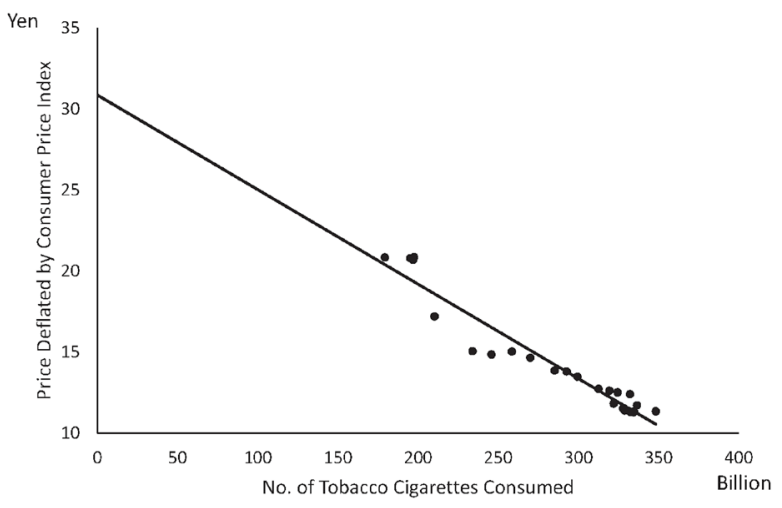

Figure 4. Plot of the price and quantity of tobacco in Japan and a fitted line. Dots indicate the price and quantity of tobacco from 1990 to 2014 according to the Japan Tobacco Association (http://www.tioj.or.jp/data/index.html). The line represents the fitted line as a result of estimating two-stage least squares. The authors created this figure from the data mentioned above.

squares method. The estimated constant term was 31.90 , and the estimated coefficient of quantity was 0.0061 . The $p$-values for both were less than 0.0004 . The determinant coefficient was 0.9187 .

On the basis of these results, the consumer surplus in 2015 was calculated to be 932 billion yen (US\$ 8.48 billion) with a $95 \%$ confidence interval (CI) ranging from 746 billion yen (US\$ 6.788 billion) to 1.20 trillion yen (US\$ 10.2 billion). Because tax revenue from the tobacco tax in 2011 was 2.38 trillion yen (US\$ 21.6 billion), the deadweight loss if smoking were prohibited in 2014 was estimated to be 3.31 trillion yen (US\$ 30.2 billion) with its 95\% CI ranging from 3.13 trillion yen (US\$ 28.5 billion) to 3.50 trillion yen (US\$ 31.8 billion).

If smoking were prohibited in 2014, the deadweight loss, which was estimated as 3.31 trillion yen (US\$ 30.2 billion), would be about 0.8 trillion yen (US\$ 7.27 billion) less than the disease burden in 2014, which was 4.10-4.12 trillion yen (US\$ 37.3-37.5 billion). Therefore, a zero-smoking policy would improve social welfare in Japan.
The estimated demand curve implies that the price elasticity of tobacco was about 0.85 when evaluated using the average price and quantity with a $95 \% \mathrm{CI}$ ranging from 0.73 to 0.92 . Studies in countries other than Japan such as India $(10,11)$, China (12), the U.S. (13), and Jordan (14) have examined the price elasticity of tobacco, yielding figures ranging from 0.212 in India to 1.15 in Jordan. In comparison, the price elasticity in the current study was moderate. Japanese studies have estimated the price elasticity of tobacco to be 0.1 to 0.3 $(15,16)$, so the current result seems high in comparison. In general, a higher price elasticity implies greater consumer surplus, and thus the additional deadweight loss due to a zero-smoking policy would be greater and might exceed the disease burden. A more accurate value for the price elasticity is needed to reach a definitive conclusion.

Moreover, the specified demand curve for tobacco seems somewhat simpler than that in previous studies. Other factors, such as total population or income, need to be taken into account when specifying the equation with which to estimate the demand curve. In this sense, a limitation of this study is that estimates should be evaluated as an average with other factors excluded. Therefore, conclusions should be similarly evaluated. The other excluded factors might strongly affect this study's estimates and conclusions. More detailed specification of the estimation equation is beyond the scope of this paper and represents a topic for further study.

The disease burden may not have been sufficiently specified. Estimates in three previous studies (1-3) did not consider the disutility of smoking to non-smokers. More detailed specification of the disease burden is also a topic for the future.

Even though this study only considered price controls on smoking, in principle, other methods of reducing smoking, such as limiting the areas in which smoking is allowed, could have the same impact on the utility of smoking to smokers if these methods also reduce the rate of smoking. However, price controls only lead to deadweight costs according to the overall welfare analysis, especially when certain externalities are taken into consideration. Therefore, this paper does not mean to suggest that price controls are the only way to reduce smoking.

In conclusion, social welfare due to a zero-smoking policy in Japan was estimated based on available data. The deadweight loss was smaller than the disease burden in 2014, leading to the conclusion that a zerosmoking policy would improve social welfare. This conclusion can be buttressed by further studies that consider other factors, such as price controls.

\section{Acknowledgements}

This study was partially funded by a Research Grant 
from the Ministry of Health, Labor, and Welfare (grant no. H27-Jyunkankitou-Ippan-006).

\section{References}

1. Institute of Health Economics and Policy. Report of a study involving a cost-benefit analysis of smoking policies. Institute for Health Economics and Policy. 1997. (in Japanese)

2. Aburatani Y. Report of a study of the effects of increasing the tobacco tax. Institute for Health Economics and Policy. 2002. (in Japanese)

3. Institute of Health Economics and Policy. Report of a study of an anti-smoking policy - Estimated costs of smoking. Institute for Health Economics and Policy. 2010. (in Japanese)

4. Ohkusa Y. Empirical research for the critical value of expenditure per QALY. Health and Society. 2003; 13:121-130. (in Japanese)

5. Neubauer S, Welte R, Beiche A, Koenig HH, Buesch K, Leidl R. Mortality, morbidity and costs attributable to smoking in Germany: Update and a 10-year comparison. Tob Control. 2006; 15:464-471.

6. Max W, Rice DP, Sung HY, Zhang X, Miller L. The economic burden of smoking in California. Tob Control. 2004; 13:264-267.

7. Sung HY, Wang L, Jin S, Hu TW, Jiang Y. Economic burden of smoking in China, 2000. Tob Control. 2006; 15(Suppl 1):i5-i11.

8. Kang HY, Kim HJ, Park TK, Jee SH, Nam CM, Park HW. Economic burden of smoking in Korea. Tob Control. 2003; 12:37-44.
9. Lee CH, Ko YC, Goggins W, Huang JJ, Huang MS, Kao EL, Wang HZ. Lifetime environmental exposure to tobacco smoke and primary lung cancer of non-smoking Taiwanese women. Int J Epidemiol. 2000; 29:224-231.

10. Selvaraj S, Srivastava S, Karan A. Price elasticity of tobacco products among economic classes in India, 2011-2012. BMJ Open. 2015; 5:e08180.

11. Kostova D, Dave D. Smokeless tobacco use in India: Role of prices and advertising. Soc Sci Med. 2015; 138:82-90.

12. Verguet S, Gauvreau CL, Mishra S, MacLennan M, Murphy SM, Brouwer ED, Nugent RA, Zhao K, Jha $\mathrm{P}$, Jamison DT. The consequences of tobacco tax on household health and finances in rich and poor smokers in China: An extended cost-effectiveness analysis. Lancet Glob Health. 2015; 3:e206-e216.

13. Goodchild M, Perucic AM, Nargis N. Modelling the impact of raising tobacco taxes on public health and finance. Bull World Health Organ. 2016; 94:250-257.

14. Sweis NJ, Cherukupalli R. Cigarette demand is responsive to higher prices: Findings from a survey of university students in Jordan. Tob Control. 2016; 25:631633.

15. Yoshida Y, Atoda N. An analysis of tobacco tax revenue in light of the effects of an increase in the Tobacco Tax on smoking. Bulletin of Konan Women's University. 2010; 47:69-76. (in Japanese)

16. Ito Y, Nakamura M. The effect of increasing tobacco tax on tobacco sales in Japan. Nihon Koshu Eisei Zasshi. 2013; 60:613-618. (in Japanese)

(Received November 15, 2017; Revised December 22, 2017; Accepted January 25, 2018) 